\title{
Serum and synovial fluid levels of angiotensin converting enzyme in polyarthritis
}

\author{
J R LOWE, ${ }^{1}$ J S DIXON, ${ }^{1}$ J A GUTHRIE, ${ }^{2}$ AND P McWHINNEY ${ }^{2}$ \\ From the ${ }^{1}$ Clinical Pharmacology Unit, Royal Bath Hospital, Harrogate, North Yorkshire; and the ${ }^{2}$ Leeds \\ General Infirmary, Great George Street, Leeds
}

SUMMARY Serum levels of angiotensin converting enzyme (ACE) activity in patients with rheumatoid arthritis (RA) $(n=48)$, osteoarthritis (OA) $(n=11)$, ankylosing spondylitis $(n=24)$, psoriatic arthritis $(n=12)$, and Behçet's syndrome $(n=20)$ were not significantly different from those of normal controls $(n=26)$. Synovial fluid ACE activity was lower in OA than in RA but was similar when corrected for protein levels. An increase in serum ACE concentration in patients with RA receiving captopril therapy is in agreement with previous results. There was some correlation of $A C E$ with erythrocyte sedimentation rate (ESR) and $C$ reactive protein (CRP) but not with clinical indices in captopril treated patients. It is suggested that the beneficial actions of captopril in the treatment of RA are not due to its activity as an ACE inhibitor, but more probably a result of captopril being an aliphatic thiol.

Key words:

It has recently been shown that captopril may show antirheumatoid activity. ${ }^{1}$ Captopril improved both clinical and laboratory measurements of disease activity in a manner similar to that of Dpenicillamine, with which captopril also shares similarities in chemical structure, metabolism, and side effects.

Captopril is an inhibitor of angiotensin converting enzyme (ACE), which converts the inactive decapeptide angiotensin I to the active octapeptide angiotensin II. In addition, ACE activity can indirectly mediate other effects which may have roles in inflammation, notably the breakdown of bradykinin, increase in prostaglandin synthesis, and release ${ }^{2}$ and immunosuppression. ${ }^{3}$ Captopril may, therefore, inhibit these processes.

Human peripheral blood monocytes have been shown to produce large quantities of ACE in vitro, ${ }^{4}$ and the authors suggested that ACE may act as a mediator of lymphocyte function. In addition, serum ACE concentrations are raised in some diseases with pathological involvement of the macrophage, e.g., sarcoidosis ${ }^{5}$ and Gaucher's disease. ${ }^{6}$ It may, therefore, be that captopril acts in rheumatoid

Accepted for publication 23 April 1986.

Correspondence to Dr J R Lowe, Clinical Pharmacology Unit,

Royal Bath Hospital, Harrogate, North Yorkshire. arthritis (RA) at least in part by the inhibition of monocyte-macrophage ACE.

Captopril may be effective in RA as a result of one or several of the above properties. It is equally possible, however, that captopril may be effective in RA through the properties of the thiol group, such as restoring of the redox balance, rather than as a consequence of its ability to inhibit ACE. Nevertheless, the dose of captopril which may be appropriate in RA is about five times lower than the required dose of D-penicillamine. This may be owing to differences in mode of action or differences in absorption or distribution of the two drugs.

If $\mathrm{ACE}$ inhibition is relevant in the treatment of RA then serum or synovial fluid (SF) ACE levels, or both, may be raised despite the absence of hypertension as a clinical feature of the disease. Furthermore, D-penicillamine is not effective in seronegative arthropathies, ${ }^{7}$ but if ACE inhibition at the macrophage level is important then captopril may be of some use in other joint diseases, particularly if serum or SF ACE levels are raised.

We have, therefore, looked at serum and SF ACE levels in active RA and serum ACE in osteoarthritis (OA), ankylosing spondylitis, psoriatic arthritis, and Behçet's syndrome. In addition, we have looked at changes in serum ACE in RA in relation to changes 
in measures of disease activity during treatment with captopril and in a control group treated with sulphasalazine. The latter has no known action against ACE, whereas high concentrations of $D$ penicillamine, for example, may inhibit ACE.

\section{Patients and methods}

\section{PATIENTS AND SAMPLES}

Venous blood samples $(5 \mathrm{ml}$ clotted) were taken from 48 patients with active RA (American Rheumatism Association (ARA) criteria), and when a significant synovial effusion was also present a specimen of synovial fluid was withdrawn (19 patients). Simultaneous serum and SF samples were also obtained from 11 patients with $\mathrm{OA}$, and serum samples from 24 patients with ankylosing spondylitis (AS) (New York criteria), 12 patients with psoriatic arthritis, and 20 patients with Behçet's syndrome (Japanese criteria). These groups of patients were receiving various drugs at the time of sampling, primarily non-steroidal anti-inflammatory agents, but not antihypertensive drugs or antirheumatoid drugs. These samples were compared with those from 26 healthy controls who were free of all medication, including antihypertensive drugs, at the time of sampling. Baseline serum samples and samples after 24 weeks' treatment with captopril ( $\leqslant 150 \mathrm{mg} /$ day) from 11 patients with active RA were also analysed for ACE activity, together with samples from nine controls treated for 24 weeks with sulphasalazine $(2.0 \mathrm{~g} /$ day $)$.

All SF samples were collected in plain tubes. In each case $50 \%$ of the sample was stored without centrifugation. The remaining $50 \%$ was centrifuged at $2000 \mathrm{rpm}$ for $10 \mathrm{~min}$ and stored in a separate plain tube.

\section{A S S A Y S}

All samples were analysed for ACE activity by the spectrophotometric method of Pre and Bladier. ${ }^{8}$ One unit of ACE activity was defined as the amount of enzyme releasing $1 \mu \mathrm{mol} \mathrm{hippurate} / \mathrm{min} / \mathrm{l}$ of serum or SF under the described reaction conditions. ACE was measured with an intra-assay precision of $\pm 11 \cdot 4 \%$. One freeze/thaw cycle did not notably affect serum or centrifuged SF results, but there was a marked difference in results for uncentrifuged SF. The assay could, therefore, be done on samples stored at $-20^{\circ} \mathrm{C}$.

Total protein concentrations were also determined for paired serum and SF samples by the Biuret method. ESR (classical Westergren) and CRP (radial immunodiffusion) were used as indices of disease activity.
CLINICAL ASSESSMENTS

Patients treated with captopril and sulphasalazine were assessed clinically by the use of the articular index $(\mathrm{AI})^{9}$ and clinical score $(\mathrm{CS}) .{ }^{10}$

\section{S T A T IS T I CS}

Comparisons of paired serum and SF samples and baseline and week 24 captopril samples were carried out with the Wilcoxon signed rank test. Between disease comparisons were made with a one way analysis of variance. SF results for RA and OA were compared using a Mann-Whitney $\mathrm{U}$ test. Correlations between $\mathrm{ACE}$ and indices of disease activity were performed with the Spearman's rank correlation coefficient.

\section{Results}

Serum ACE activity for the normal controls and the various disease groups is indicated in Table 1 . The median result and range of results for each patient group were very similar. No disease group showed any statistically significant difference from the control group. The overall range of results was 20-135 $\mathrm{U} / \mathrm{l}$, with median results in the various groups ranging from $52 \mathrm{U} / 1$ (RA) to $65 \mathrm{U} / 1$ (psoriatig arthritis).

All SF samples and their matched sera wex assayed for total protein in order to express ACE activity per unit of protein in addition to the absolute ACE activity. When uncentrifuged SF was compared with centrifuged SF after one freeze/thaw cycle for the RA samples $(n=19)$ two patients had higher ACE levels in the uncentrifuged SF, but nine results for the latter had fallen to $5 \mathrm{U} / \mathrm{l}$. This comparison and a comparison of SF (centrifuged) with serum ACE is shown in Table 2. Absolute $A C E$ activity was greater in serum (median $=50 \mathrm{U} / \mathrm{l}$ ) than in SF (median $=30 \mathrm{U} / \mathrm{l}$ ), but was similar when corrected for protein (median $=0.67 \mathrm{U} / \mathrm{g}$ in both fluids). Absolute ACE activity in the $11 \mathrm{OA}$ samples showed lower SF (centrifuged) levels than seen in the RA samples (OA median $=18 \mathrm{U} / \mathrm{l}, \mathrm{p}<0 \cdot 01$ ), but when corrected for protein levels there was no

Table 1 Serum ACE activity (U/l) in normal controls compared with patients with various arthropathies

\begin{tabular}{lll}
\hline Disease & Median & Range \\
\hline Normal controls & 55 & $20-120$ \\
Rheumatoid arthritis & 52 & $20-131$ \\
Ankylosing spondylitis & 59 & $35-125$ \\
Behçet's syndrome & 54 & $22-135$ \\
Psoriatic arthritis & 65 & $29-81$ \\
Osteoarthritis & 57 & $40-79$
\end{tabular}


Table 2 Comparison of serum and SF ACE activity in $R A(n=19)$

\begin{tabular}{|c|c|c|c|c|}
\hline & \multicolumn{2}{|c|}{ Absolute ACE activity (U/l) } & \multicolumn{2}{|c|}{ ACE activity corrected for protein $(U / g)$} \\
\hline & $\begin{array}{l}\text { Wilcoxon rank } \\
\text { sum test }\end{array}$ & Correlation & Wilcoxon rank sum test & Correlation \\
\hline $\begin{array}{l}\text { Serum } v \text { SF (spun) } \\
\text { SF (spun) } v \text { SF (unspun) }\end{array}$ & $\begin{array}{l}\mathrm{p}<0.05 \\
\mathrm{p}<0.01\end{array}$ & $\begin{array}{l}0 \cdot 293 \\
0 \cdot 511\end{array}$ & $\begin{array}{l}\mathrm{NS} \\
\mathrm{p}<0.01\end{array}$ & $\begin{array}{l}0 \cdot 262 \\
0 \cdot 308\end{array}$ \\
\hline
\end{tabular}

significant difference between the two diseases (OA median $=0.61 \mathrm{U} / \mathrm{g}$ ).

The 11 patients with RA treated with captopril for 24 weeks showed a marked increase in measured ACE activity (Table 3). Absolute ACE activity increased in 10 patients, but when corrected for protein levels all 11 patients showed an increase $(p<0 \cdot 01)$. The baseline ACE levels for these patients did not correlate significantly with accepted measures of disease activity, including the AI, CS, ESR, or CRP (Table 4a). Although ESR and CRP correlated well with one another, neither correlated well with AI (Table 4b). The correlations after 24 weeks of treatment were better and suggested a weak relationship between acute phase reactants and ACE levels, though not between clinical mea-

Table 3 Serial change in serum ACE activity in RA during therapy (median and range)

\begin{tabular}{|c|c|c|}
\hline \multirow[t]{2}{*}{ Parameter } & \multicolumn{2}{|l|}{ Treatment } \\
\hline & Captopril $(n=11)$ & Sulphasalazine $(n=9)$ \\
\hline \multicolumn{3}{|c|}{$\begin{array}{l}\text { Absolute ACE } \\
\text { (U/l) }\end{array}$} \\
\hline Week 0 & $56(21-106)$ & $69(29-151)$ \\
\hline Week 24 & $83(42-264)$ & $67(37-108)$ \\
\hline p Value & $<0.01$ & NS \\
\hline \multicolumn{3}{|c|}{$\begin{array}{l}\text { ACE corrected } \\
\text { for protein } \\
(\mathrm{U} / \mathrm{g})\end{array}$} \\
\hline Week 0 & $0.67(0 \cdot 24-1 \cdot 13)$ & $0 \cdot 87(0.41-2 \cdot 22)$ \\
\hline Week 24 & $1.05(0.48-2.97)$ & $0.89(0.48-1.61)$ \\
\hline p Value & $<0.01$ & NS \\
\hline
\end{tabular}

Table 4a Correlations between ACE activity and disease activity in captopril treated patients

\begin{tabular}{llll}
\hline Parameter & Week 0 & Week 24 & Week 24-week 0 \\
\hline AI & 0.130 & 0.136 & -0.094 \\
CS & NA & 0.221 & 0.070 \\
ESR & -0.406 & $-0.733^{*}$ & -0.421 \\
CRP & -0.321 & -0.542 & -0.455 \\
\hline
\end{tabular}

${ }^{*} \mathrm{p}<0.05$.

$\mathrm{NA}=$ not applicable (all CS week 0 results $=100$ ).
Table 4b Correlations between measurements of disease activity in captopril treated patients

\begin{tabular}{llcl}
\hline Correlation pair & Week 0 & Week 24 & Week 24-week 0 \\
\hline AI $v$ CS & NA & $-0.685^{*}$ & $-0.791^{* *}$ \\
AI $v$ ESR & -0.385 & 0.239 & $0.736^{*}$ \\
AI $v$ CRP & -0.052 & 0.388 & 0.209 \\
CS $v$ ESR & NA & -0.421 & $-0.812^{* *}$ \\
CS $v$ CRP & NA & -0.194 & -0.300 \\
ESR $v$ CRP & $0.782^{* *}$ & $0.773^{* *}$ & 0.342 \\
\hline
\end{tabular}

${ }^{*} \mathrm{p}<0.05 ;{ }^{* *} \mathrm{p}<0 \cdot 01$

sures and ACE (Table 4a). The correlations between the week 24 data corrected for baseline value, representing changes during therapy, were weak for the four comparisons, though the smaller the change in ACE, the worse the patient response in terms of ESR and CRP. As might be expected the changes in ESR correlated well with the changes in AI and CS (Table 4b). The nine control patients with RA treated with sulphasalazine for 24 weeks showed no change in ACE activity (Table 3) but marked improvement in AI, CS, ESR, and CRP.

\section{Discussion}

Serum ACE activity appears to be normal in a selection of joint diseases, including RA. SF results in RA and a control group (OA) suggest that the higher ACE activity in RA SF is a consequence of the higher total protein resulting from increased vascular permeability in the joint. Furthermore, if SF samples are not centrifuged then the freeze/thaw action appears to cause variable release of an endogenous $\mathrm{ACE}$ inhibitor, probably originating from cell lysis, and hence centrifugation is necessary to determine SF ACE levels.

In view of the beneficial action of captopril in RA it was thought that it might act, at least in part, by ACE inhibition, but the presence of normal serum and SF ACE levels in RA suggests that this is unlikely. The increase in serum ACE seen after 24 weeks of captopril therapy, but not after sulphasalazine therapy, in patients with RA probably results 
from a negative feedback mechanism causing increased ACE synthesis. ${ }^{11}$ The increase (week 24-week 0) in ACE correlated better with the decreases (week 24-week 0) in ESR and CRP than with the decrease in AI or the increase in CS. This apparent weak inverse association between ACE and acute phase reactants means that a possible role for $\mathrm{ACE}$ in acute inflammatory processes cannot be dismissed. Nevertheless, the absence of change in ACE in control patients treated with sulphasalazine, despite significant improvement in AI, CS, ESR, and CRP, would suggest otherwise, and a larger patient series treated with captopril is clearly required to clarify the point.

Fresh serum samples from hypertensive patients after a single dose of captopril show a marked decrease in ACE activity, ${ }^{1}$ but this inhibition by captopril is lost upon storage of samples at $-20^{\circ} \mathrm{C} .^{12}$ Hence the results presented here essentially reflect ACE concentration rather than ACE activity. The observed percentage increase is similar to that reported previously ${ }^{11}$ for higher doses of captopril given to hypertensive patients, but the handling of captopril by patients with RA may be different owing to the depressed serum sulphydryl levels and changes in several protein concentrations. Furthermore, failure to find any correlation between circulating immune complexes and raised serum ACE in pulmonary sarcoidosis ${ }^{13}$ also suggests that ACE may not be involved in the pathogenesis of chronic inflammatory diseases. It is difficult, however, to draw close comparisons with data obtained from other disease states.

The patients with RA treated with captopril were also receiving concomitant non-steroidal antiinflammatory drug therapy, which may affect the interaction of captopril with ACE. Aspirin may partially inhibit the interaction ${ }^{14}$ and acute indomethacin pretreatment significantly decreases the acute hypotensive effect of captopril in volunteers and in hypertensive patients. ${ }^{15}$ Clearly, a more definitive way of indicating the mode of action of captopril will be to treat a group of patients with RA with a non-thiol ACE inhibitor. Enalapril is a new ACE inhibitor which does not possess a thiol group and its administration to three normotensive patients with RA failed to improve clinical features of the RA, ESR, or rheumatoid factor after 16 weeks' therapy. ${ }^{16}$ Nevertheless, a more detailed study of a non-thiol ACE inhibitor in the treatment of RA would be an appropriate step to help clarify some of these issues.

In conclusion, the probable effectiveness of captopril in the treatment of RA is more likely to be exerted as a consequence of the molecule being an aliphatic thiol ${ }^{17}$ rather than it being an ACE inhibitor. It is also unlikely that captopril would be effective in the treatment of seronegative arthropathies.

The authors wish to thank $\mathrm{Dr} \mathrm{H} \mathrm{A}$ Bird for helpful discussion and Mrs R H Schofield for secretarial assistance. The Clinical Pharmacology Unit gratefully acknowledges the financial support of Roche Products Limited.

\section{References}

1 Martin M F R, McKenna F, Bird H A, Surrall K E, Dixon J S Wright V. Captopril: a new treatment for rheumatoid arthritis. Lancet 1984; i: 1325-7.

2 Swartz S L, Williams G H, Hollenberg N K, Levine L, Dluhy R G, Moore T J. Captopril-induced changes in prostaglandin production: relationship to vascular responses in normal man. $J$ Clin Invest 1980; 65: 1257-64.

3 Johnsen S A, Aurell M. Immunosuppressive action of captopril blocked by prostaglandin synthetase inhibitor. Lancet 1981; i: 1005.

4 Friedland J, Setton C, Silverstein E. Induction of angiotensin converting enzyme in human monocytes in culture. Biochem Biophys Res Commun 1978; 83: 843-9.

5 Lieberman J. Evaluation of serum angiotensin converting enzyme (ACE) in sarcoidosis. Am J Med 1975; 59: 365-72.

6 Lieberman J, Beuther E. Elevation of serum angiotensin converting enzyme in Gaucher's disease. N Engl J Med 1976. 294: $1442-4$.

7 Bird H A, Dixon A St J. Failure of D-penicillamine to affece peripheral joint involvement in ankylosing spondylitis or HL B27-associated arthropathy. Ann Rheum Dis 1977; 36: 289.

8 Pre J, Bladier D. A rapid and sensitive spectrophotometric method for routine determination of serum angiotensin 1 converting enzyme activity. IRCS Med Sci 1983; 11: 220-1.

9 Ritchie D M, Boyle J A, Mclnnes J M, et al. Clinical studies with an articular index for the assessment of joint tenderness in patients with rheumatoid arthritis. $Q J$ Med 1968; 37: 393-406.

10 McConkey B, Crockson R A, Crockson A P. The assessment of rheumatoid arthritis: a study based on measurements of the serum acute phase reactants. $Q J$ Med 1972; 41: 115-25.

11 Boomsma F, De Bruyn J H B, Derkx F H M, Schalekamp M A D H. Opposite effects of captopril on angiotensin Iconverting enzyme 'activity' and 'concentration'; relation between enzyme inhibition and long-term blood pressure response. Clin Sci 1981; 60: 491-8.

12 Kamoun P P, Bardet J I, Di Giulio .S, Grunfeld J P. Measurement of angiotensin converting enzyme in captopriltreated patients. Clin Chim Acta 1982; 118: 333-6.

13 Romer F K, Solling J. Relationship between circulating immune complexes and angiotensin-converting enzyme in pulmonary sarcoidosis. Acta Med Scand 1981; 210: 299-303.

14 Melli M, Türker R K. Reversal by acetylsalicylic acid of the captopril-induced inhibition of angiotensin converting enzyme in the hindquarters of guinea-pig. Arch Int Pharmacodyn Ther 1982; 257: 87-93.

15 Silberbauer K, Stanek B, Templ H. Acute hypotensive effect of captopril in man modified by prostaglandin synthesis inhibition. Br J Clin Pharmacol 1982; 14: 87-93S.

$16 \mathrm{Jaffe} I$. Angiotensin converting inhibitors in rheumatoid arthritis. Arthritis Rheum 1984; 27: 840.

17 Drury P L, Rudge S R, Perrett D. Structural requirements for activity of certain 'specific' antirheumatic drugs: more than a single thiol group? Br J Rheumatol 1984; 23: 100-6. 